REVISTA DE ESTUDOS EM ARTES CÊNICAS

E-ISSN 2358.6958

\title{
A cena americana de Mary Overlie e a origem do Six Viewpoints
}

Miriam Rinaldi

\section{Para citar este artigo:}

RINALDI, Miriam. A cena americana de Mary Overlie e a origem do Six Viewpoints. Urdimento - Revista de Estudos em Artes Cênicas, Florianópolis, v. 3, n. 42, dez. 2021.

do) DOI: http:/dx.doi.org/10.5965/1414573103422021e0108

Este artigo passou pelo Plagiarism Detection Software | iThenticate 
A cena americana de Mary Overlie ${ }^{1}$ e a origem do Six Viewpoints ${ }^{2}$

Miriam Rinaldi ${ }^{3}$

\title{
Resumo
}

Em maior ou menor grau, a improvisação é elemento inerente das artes cênicas. No entanto, os conceitos que orientam a construção de enunciados de improvisação refletem os valores e os conceitos de sua época. O Six Viewpoints, sistema de improvisação articulado por Mary Overlie, foi tornado público em 1978 e desde então veio se consolidando, e hoje participa da formação de muitos artistas no Brasil. Sua origem, no entanto, não está dissociada de suas circunstâncias históricas. Nesse artigo de caráter biográfico, buscou-se a conexão entre a prática e a teoria, desenhando alguns traços da trajetória da artista Mary Overlie desde sua infância em Montana até 1980, em Nova Iorque.

Palavras-chave: Six Viewpoints. Mary Overlie. Grand Union. Mabou Mines.

\section{The American scene of Mary Overlie and the origin of the Six Viewpoints}

\begin{abstract}
To a greater or lesser degree, improvisation is an inherent element of the performing arts. However, the concepts that guide the construction of improvisation utterances reflect the values and concepts of their time. Six Viewpoints, an improvisation system articulated by Mary Overlie, was made public in 1978 and since then it has been consolidated and today participates in the formation of many artists in Brazil. Its origin, however, is not dissociated from its historical activities. In this biographical article, a connection between practice and public theory was sought, drawing some traces of the trajectory of the artist Mary Overlie from her childhood in Montana to 1980 in New York.
\end{abstract}

Keywords: Six Viewpoints. Mary Overlie. Grand Union. Mabou Mines.

\footnotetext{
${ }^{1}$ Este artigo deriva de minha tese de doutorado, defendida em 2016, na Universidade de São Paulo (USP), sob o título Teoria e prática do Viewpoints, sob orientação do professor Jacó Guinsburg.

2 Revisão ortográfica e gramatical do artigo realizada por Liliana Junqueira. Graduada em Letras PortuguêsInglês pela Universidade Mackenzie-SP.

${ }^{3}$ Doutorado em Artes pela Escola de Comunicações e Artes da Universidade de São Paulo (ECA/USP). Mestrado pela mesma universidade. Graduada em Educação Artística com Habilitação em Teatro pelo Instituto de Artes da Universidade Estadual Paulista (UNESP). Formada pela Escola de Arte Dramática (EAD/USP). miriamrinaldi2013@gmail.com

http://lattes.cnpq.br/2175330536700349

htps://orcid.org/0000-0002-6957-2192
} 
La escena estadounidense de Mary Overlie y el origen de lo Six Viewpoints

\section{Resumen}

En mayor o menor grado, la improvisación es un elemento inherente a las artes escénicas. Sin embargo, los conceptos que guían la construcción de enunciados de improvisación reflejan los valores y conceptos de su época. Six Viewpoints, un sistema de improvisación articulado por Mary Overlie, se hizo público en 1978 y desde entonces se ha consolidado y hoy participa en la formación de muchos artistas en Brasil. Su origen, sin embargo, no se disocia de sus actividades históricas. En este artículo biográfico se buscó una conexión entre la práctica y la teoría pública, trazando algunas huellas de la trayectoria de la artista Mary Overlie desde su infancia en Montana hasta 1980 en Nueva York.

Palabras clave: Six Viewpoints. Mary Overlie. Gran Unión. Minas Mabou. 
Eu não reinvidico a invenção deste trabalho, mas eu me autoproclamo criadora dos Six Viewpoints

(Mary Overlie) $^{4}$

Tomei contato com o Viewpoints na ocasião da montagem do espetáculo Apocalipse 1,11, quando então era integrante do grupo Teatro da Vertigem. Anos depois, mudei-me para Nova Iorque e tive, então, a oportunidade de realizar cursos com Anne Bogart e a SITI Company, e também acompanhar uma disciplina de Mary Overlie na Experimental Theatre Wing, um compacto de dois meses dirigido aos alunos da graduação na TISCH School da New York University (NYU). Além da experiência prática, tive acesso aos arquivos da TOFT (Theatre on Film and Tape) na Public Library for the Performing Arts, em Nova Iorque, o que me possibilitou o estudo de material diverso (críticas, artigos e entrevistas) relacionados à Mary Overlie, além da assistência de registros em vídeo de seus experimentos em dança, espetáculos realizados em parceria com o Mabou Mines e outros trabalhos em seu início de carreira.

Interessava-me compreender as bases conceituais e o contexto artístico em que o Six Viewpoints ${ }^{5}$ emergiu em meio às inovadoras experimentações entre as linguagens que eclodiram a partir de 1960. A partir do enquadramento histórico centrado na figura de Mary Overlie, o artigo vasculha o terreno do pósmodernismo, em especial em obras dos expoentes da dança da Judson Dance Theater, em busca de pistas que fundamentem o pensamento desse sistema que integra seis elementos ligados à noção do tempo e espaço. Neste artigo, interrompo o recorte temporal até 1978, pois a partir de então, novos desdobramentos se deram, inclusive a partir da convivência entre Mary Overlie e Ane Bogart por ocasião de duas montagens que realizaram juntas com os alunos da NYU, Artouriste South Pacific ${ }^{6}$.

\footnotetext{
${ }^{4}$ I claim not to have invented this work but I do proclaim myself the originator of The Six Viewpoints. (Tradução nossa). Disponível em https://sixviewpoints.com/theproject Acesso em: 15 out. 2021.

${ }^{5}$ Utilizarei como padrão o artigo no singular antes de Six Viewpoints, pois refiro-me ao sistema de improvisação e não aos seis elementos que o compõem.

${ }^{6}$ Em 1979, apenas um ano após a primeira aula pública do Six Viewpoints, Bogart, que acabara de concluir seu mestrado, é convidada para lecionar no Experimental Theater Wing, curso que acabava de surgir na New York University, ao lado de Overlie. Juntas, realizaram duas montagens: Artourist, uma codireção em teatro-
} 
Outro fator que impulsionou a pesquisa na ocasião, mas que persiste ainda que em menor escala nos dias de hoje, foi o fato de haver mais material disponível ao pesquisador sobre o Viewpoints de Anne Bogart que o Six Viewpoints de Mary Overlie.

A repercussão dos Viewpoints deve muito à produção intelectual e artística de Anne Bogart. A SITI Company produziu mais de trinta peças ao longo de seus vinte e dois anos de existência, difundindo as possibilidades estéticas que a prática gerou, bem como os workshops oferecidos ao público ao longo de todos os anos de atividade da companhia. Também a produção editorial é díspar, seja em número de artigos, como em ineditismo: The Viewpoints Book, a practical guide to Viewpoints and Composition de Anne Bogart e Tina Landau é de 2005, enquanto Standing in space - the Six Viewpoints theory and practice, de Mary Overlie, data de 2016.

\section{Montana}

Montana, estado situado na fronteira com o Canadá, é caracterizado por grandes planícies e por elevada cadeia de montanhas rochosas. Foi nesse cenário que Mary Overlie nasceu no ano de 1946. Na cidade de Bozeman, onde foi criada, há alguns personagens importantes como, por exemplo, o casal de artistas plásticos Gennie e Robert DeWeese. Para Mary, os DeWese foram seus verdadeiros tutores, pois lhe ensinaram o prazer da experimentação e a perseguir com responsabilidade suas próprias ideias?

Da convivência com o casal vizinho da família, Mary Overlie entrou em contato com um numeroso grupo de artistas. Ela ouvia longas discussões a respeito de temas tais como forma, processo de criação e liberdade de expressão. Foi assim que ela compreendeu que a comunicação pode ocupar um lugar vital na arte.

A influência do casal DeWeese não se dava apenas através de sua arte, mas também de seu estilo de vida: a boemia plena de discussões sobre arte e cultura,

dança de 1980, e South Pacific, direção de Bogart e coreografia de Overlie, de 1984.

7 Disponível em: https://sixviewpoints.com/thesstems Acesso em: 15 out. 2021. 
reunindo artistas, filósofos e cientistas, colegas da universidade onde Robert lecionava (Schontzler, 2011). Eles misturavam arte e vida de uma forma que a comunidade artística de Montana não havia visto e incentivavam todas as linguagens artísticas: dança, teatro, escultura ou pintura. O ateliê, a casa, os filhos, os desenhos, os amigos e a arte formavam uma só coisa.

Essa liberdade contrastava com o contexto político da época, marcado, por volta de 1950, pelo macartismo8. Bozeman estava entre as cidades mais conservadoras. Para se ter uma ideia, Eleonor Roosevelt, a ex-primeira dama e defensora das Nações Unidas e dos direitos humanos, foi impedida de falar na faculdade da cidade por ser considerada controversa e comunista. Foi nessa comunidade que o casal DeWeese expôs não apenas uma nova arte, mas um jeito libertário de viver e valorizar a vida. Mary Overlie afirma a importância do casal naquele cenário:

Eu testemunhei cada um dos meus tutores em um lugar especial no mundo, tendo que lutar pela liberdade para manter uma visão aberta da vida. Eu os vi trabalhando arduamente para manter sua credibilidade em uma sociedade que não se sentia confortável com pessoas que criavam suas próprias ideias Meus tutores me ensinaram que a força verdadeira é baseada na flexibilidade de uma mente aberta, da coragem de ser maleável para aceitar experiências e ideias e a disciplina do pensamento autocrítico na busca por clareza. Estas posturas abertas formam uma estrutura central na minha vida e continuam a iluminar a forma na qual ensino o Six Viewpoints. ${ }^{9}$

Além da intensa produção em diferentes suportes, o casal de artistas também ficou conhecido internacionalmente por meio do livro de Robert Pirsig10 Zen and the art of the motorcycle maintenance (Zen e a arte da manutenção de

\footnotetext{
8 O macartismo define um período de intensa patrulha anticomunista ocorrida entre o final dos anos 1940 até meados dos anos 1950. O termo foi cunhado para criticar as ações do senador americano Joseph McCarthy.

9 I witnessed each of my tutors stand times in a special place in the world, having to fight for the freedom to hold an open view on life. I watched them work very hard to maintain credibility in a society that did not feel comfortable with people creating their own ideas. My tutors taught me that real strength is built out of the flexibility of an open mind, the courage to be fluid in accepting experiences and ideas and the discipline of self-critical thinking to strive for clarity. These open views formed a central structure in my life and continue to inform the manner in which | teach the Six Viewpoints. (Tradução nossa). Disponível em: https://sixviewpoints.com/theproject Acesso em: 15 out. 2021.
}

10 Robert Pirsig foi uma criança superdotada e ingressou na universidade aos 15 anos. Após servir na Coreia do Sul, retornou para Minnesota e concluiu o curso de Filosofia. Em 1950, parte para a Índia, estudar filosofia oriental na Banaras Hindu University. 
motocicletas), de 1974, que vendeu mais de cinco milhões de exemplares em todo o mundo. A história relata uma viagem que pai e filho percorrem de motocicleta, acompanhados de um casal de amigos, cruzando o país de Minnesota até Califórnia. Longos trechos foram inspirados em conversas do autor com seus velhos amigos Bob e Gennie DeWeese, personagens do livro.

A narrativa instiga por alternar momentos da relação entre pai e filho, da paisagem e das pessoas que cruzam a história com reflexões a respeito do significado da existência, além da forte rejeição ao consumismo. A importância do livro não se deve, no entanto, ao fato de ter tornado conhecido o casal DeWeese, mas por expressar o pensamento alternativo da cultura beatnick ${ }^{11}$ e da contracultura. A longa viagem de costa a costa em suas diversas situações, são pretexto para que o autor explore reflexões filosóficas e religiosas. Ainda hoje, Mary Overlie considera o livro de Robert Pirsig como uma das obras fundamentais para compreensão dos Six Viewpoints.

O ambiente intelectual dos DeWeese era contrabalançado, no entanto, com uma infância vivida a céu aberto, ao lado de cinco irmãos, todos mais novos. Mary Overlie orgulhava-se de suas habilidades corporais: sozinha, aprendeu a controlar um bote pelas corredeiras torrenciais de Bozeman e a andar em uma bicicleta de adulto, sem pneus e sem banco (Sommer, 1980, p.50).

Seu desembaraço físico não the assegurou um perfil de pessoa comunicativa. Ao contrário, sua personalidade tímida the garantiu o mergulho radical para desenvolvimento de suas ideias e levou trinta e oito anos para sua estruturação total que culminou com a edição do livro Standing in Space, publicado um ano antes de sua morte.

Foi seguindo os passos de uma amiga que Mary Overlie iniciou, aos nove anos, as aulas de balé. A classe era pequena, ao todo quatro garotas, e seu professor, Harvey Jung, havia sido membro da New York City Opera Ballet. Ele acabava de retornar para Montana, depois de ter dançado com o já famoso Jerome Robins e em outros musicais da Broadway. Apesar de muito disciplinada, até os dezessete

${ }^{11}$ Beatnick ou Beat Generation são pessoas nascidas entre 1928 e 1945 e refere-se, principalmente, a um gênero literário que acabou por caracterizar um estilo de vida, e que perdurou até meados dos 1960 tendo Jack Kerouac como um de seus expoentes. 
anos, diz nunca ter visto um espetáculo de dança.

No começo, Mary Overlie não estava muito interessada no balé, mas the chamou a atenção o fato de ter um alvo físico a ser alcançado, como fazer um plié perfeito. Começou a interessar-se pela estrutura do movimento, dedicandose com obstinação. Harvey Jung, além do trabalho de barra próprio do balé, treinava suas alunas para a improvisação incentivando-as a dançar uma cor ou o movimento de um pássaro, por exemplo. Mas nunca a dançar uma sequência de passos (Overlie apud Sommer, 1980, p.48), de tal forma que detinham o vocabulário, mas não a sintaxe; não sabiam como o balé combinava seus movimentos em uma gramática própria. Como quem cria um novo idioma, Mary Overlie utilizou, desde cedo, os códigos do balé clássico para comunicar-se livremente por meio da improvisação.

Aos dezessete anos, queria ir para Nova lorque, então o centro da dança, mas a única pessoa que ela conhecia fora de sua cidade morava em Berkeley, em São Francisco, berço do movimento hippie. Então, em 1964, com apenas 17 anos e vinte e cinco dólares no bolso, Mary Overlie pegou uma carona e chegou à Califórnia.

\section{São Francisco 1964 - 1969}

O ambiente familiar não preparou Mary Overlie para seguir uma carreira, uma profissão ou mesmo para conseguir um emprego: “Eu era uma índia selvagem que virou dançarina" (Overlie apud Sommer, 1980, p.46)12.

Chegando a Berkeley, e com tão pouco dinheiro, Mary Overlie logo se engajou em uma comunidade de artistas, a Jane Lapiner Dance Company. Jane e seu parceiro, David Simpson, junto a outros membros do San Francisco Mime Troupe, acabavam de formar uma comunidade em Haight Ashbury, distrito de São Francisco, para viver na prática os princípios políticos e sociais que o Mime Troupe defendia. Esse grupo chamava-se Diggers, nome inspirado em uma comunidade protestante de 1649 que abolia práticas consumistas bem como a noção de propriedade privada. O ator Peter Coyote, um dos líderes do grupo, via no Diggers

\footnotetext{
12 I was a wild Indian who happened to dance. (Tradução nossa).
} 
um prolongamento da visão de mundo alternativo do Mime Troupe, no qual vida e arte estavam correlacionadas.

Ronnie G. Davis, dançarino e mímico que fundou o Mime Troupe em 1965, descreveu a atividade do grupo como "teatro de guerrilha" (Precioso, 2018, p. 126). Sua ação abordava temas engajados, como a guerra do vietnã e o racismo e era marcada por constantes confrontos com a polícia em apresentações em parques e ruas. O grupo usava a linguagem da commedia dell'arte e da manipulação de bonecos superdimensionados para adaptar peças de Molière e Brecht, por exemplo, para fins próprios, sempre na tentativa de trazer à tona uma discussão social e política. Davis tinha em mente três ações por meio do teatro: ensinar, incitar à transformação e ser um exemplo de mudança.

O Diggers misturava teatro de rua, ação social e happenings para difundir suas ideias, principalmente a recusa do consumismo e do capitalismo, suas principais bandeiras. Um de seus projetos, conhecido como Free City, tinha o princípio da liberdade e da gratuidade e originaram uma série de ações, tais como: Free Food, em que se distribuía comida de graça em parques e em ruas, Free Store, em que tudo podia ser levado sem nenhum custo e ainda Free Press, Free Medical Clinic e Free Fishing. Para gerar fundos para essas ações, eles arrecadavam 1\% do lucro de shows de bandas de rock emergentes nesse período como Greateful Dead e Jefferson Airplaine, além de arrecadar pequenas cotas de empresários locais. O Diggers foi um dos grupos precursores do movimento hippie, ganhando rápida repercussão.

Mary Overlie teve aulas com David Wood e com Betty Jones. Wood era coreógrafo, dançarino, professor e fundador do curso de dança na Universidade de Berkeley. Ele pertenceu à companhia de Martha Graham, na qual foi também solista. Jones foi cofundadora e membro da Jose Limón Dance Company e participou de doze das trinta coreografias assinadas pela dupla Humphrrey/Limón. Obteve destaque pela atuação em The Moor's Pavane, baseada em Otelo de W. Shakespeare, em que interpretava Desdemona e com a qual ganhou reconhecimento também como professora de dança, provendo à técnica Limón uma abordagem pessoal. 
De 1966 a 1969, Mary Overlie trabalhou alternadamente no Mime Troupe e na Jane Lapiner Dance Company. Apesar de ser avessa a certos hábitos hippies como o consumo de drogas ou a vida em comunidade (Bogart, 2012, p.474), sua visão não hierárquica na produção artística, o regime anárquico ou a defesa pela liberdade que viria instaurar em suas aulas pode ter tido ali um ponto de partida.

O ano de 1969 foi agitado para Overlie. Além do Mime Troupe e da companhia de Lapiner, participou do grupo de Theresa Dickinson, outra jovem dançarina do movimento contracultura de São Francisco, que anos mais tarde, ao lado de Terry Sendgraff e Rodhessa Jones, formaria o coletivo Tumbleweed, um dos grupos mais influentes da Califórnia.

Mary Overlie buscava avanços técnicos e corporais e para isso, fez aulas de dança moderna e de balé clássico, mas sem muita empolgação. Toda vez que percebia que o vocabulário das aulas invadia suas improvisações, ela abandonava o curso. Desse modo, continuou fiel à sua ideia do que era dança, embora não soubesse exatamente o que estava procurando. Ela queria manter-se ativa criativamente e em constante contato com o que sentia e pensava.

Então, em 1970, Mary Overlie conheceu Margaret Jenkins, que nesse mesmo ano retornava à São Francisco e inaugurava seu próprio estúdio depois de mais de doze anos dando aulas na escola de Merce Cunningham, esse que viria a ser uma referência, um marco de sua geração: "Eu penso que sou fascinada por uma arte que seja elementar [...] O trabalho de Cunningham é sobre tempo e espaço. Não tem história. Não tem emoção" (Bogart, 2012, p.475) ${ }^{13}$.

Pouco tempo depois, Mary Overlie conhece Yvonne Rainer, Barbara Dilley, David Gordon e Steve Paxton, membros do grupo de dança Grand Union que vieram de Nova Iorque para participar do San Francisco Dancers Workshop, um curso de verão ministrado pela dançarina Ann (mais tarde Anna) Halprin. Ann dançou com Martha Graham e Doris Humprey, mas, insatisfeita com a dança moderna, propôs expandir os limites da técnica por meio da improvisação. Foi justamente na busca de novas estruturas de improvisação que os artistas do 
Grand Union estavam interessados. Apesar de Ann Halprin ser uma dançarina extremamente influente no cenário dos anos de 1960, Mary Overlie nunca se interessou, nem sequer se aproximou do belo deck onde os cursos e as apresentações ocorriam, repudiando assim qualquer envolvimento com a dança moderna (Bogart, 2012, p.474). O mesmo não aconteceu quando assistiu Yvonne Rainer e o Grand Union: "Quem são essas pessoas? Essa mulher é incrível. Eu vou segui-la até o fim do mundo, ela querendo ou não. Eu nunca tinha feito isso. Nunca havia escolhido ninguém para me guiar ou imaginado que eu poderia ser guiada para algum lugar" (Sommer, 1980, p.46)

Tal experiência foi decisiva para a criação do Six Viewpoints. Segundo Mary Overlie, o trabalho do Grand Union pode ser considerado transformador, pois toda a história da dança ocidental foi consolidada em uma estrutura hierárquica em que a figura do coreógrafo ocupa o ponto mais alto e o trabalho do Grand Union subvertia totalmente essa estrutura, pois inauguraram a ideia de que cada dançarino é um artista com voz própria: “Eu, finalmente, poderia ser vista como uma artista, me levar a sério, criar meus próprios parâmetros de trabalho, minha poética e meu próprio processo de criação" (Bogart, 2021, p. 477)15.

Nesse mesmo período, Barbara Dilley (na ocasião Lloyd) estava ministrando um curso e reunindo pessoas para uma apresentação no Whitney Museum. Como Mary Overlie havia participado de um de seus workshops, Barbara convidou-a para seguir para Nova Iorque. O grupo estava ensaiando o Continuous Project Altered Daily - CP-AD. Pode-se fazer um paralelo entre essa e a experiência de anos mais tarde, por ocasião da montagem de Blind Bird Dance Box, em 1988. Tal qual o primeiro professor de balé de Mary Ovelie, Barbara Dilley recusou-se a passar-lhe os movimentos, preferindo instruções verbais e escritas. A ideia geral era dançar a energia do espaço, como por exemplo, dançar os redemoinhos, as direções e as correntes da sala e escalar até o topo dos caixotes de madeira, extremamente frágil, vendada, dançando no limite e equilibrando braços e pernas. Mary Overlie

\footnotetext{
${ }^{14}$ Who are these people? That woman is amazing. I'll follow her to the ends of the Earth, whether she wants me or not. And l'd never done that, never adopted someone, thinking they could lead me somewhere. (Tradução nossa).

15 I could be seen as an artist and I take myself seriously and come up with my own statements, my own prose, my own work process. (Tradução nossa).
} 
conta que a experiência era ao mesmo tempo exaustiva e aflitiva e se deu conta de quão distante estava da dança que perseguia. Era como se o processo de criação com Barbara Dilley tivesse aterrado seus pés em uma longa estrada que viria, a partir de então, percorrer (Sommer, 1980, p.46).

São Francisco inseriu Mary Overlie no campo profissional, seja pela ampliação do repertório técnico da dança como pela rede de artistas das mais diversas linguagens com quem teve contato. Mesmo sua ida para Nova Iorque não enfraqueceu uma aliança identitária que teve seu início em São Francisco e se mostrou definitiva em sua carreira.

\section{Nova Iorque - Grand Union}

Apesar de Overlie insistir que a maior influência sobre o Six Viewpoints foi a paisagem minimalista de Montana (Bogart, 2012, p.472) e os artistas com quem conviveu no atelier dos DeWeese, é indubitável que sua técnica está largamente alicerçada no pensamento da dança pós-moderna e nas inovações trazidas pelos artistas da Judson Church Dance Movement, em particular do Grand Union.

O Grand Union foi um coletivo formado por coreógrafos e dançarinos que atuaram juntos entre 1970-76, dentre eles Becky Arnold, Douglas Dunn, David Gordon, Barbara Dilley, Steve Paxton e Yvone Rainer em uma formação flutuante entre seus integrantes. Sua principal marca foi questionar a teatralidade da dança enquanto linguagem, realizando trabalhos na zona limite entre o teatro e a performance. Boa parte de seus componentes já se conhecia das aulas de Merce Cunningham, sendo que três deles já haviam dançado em sua companhia. Yvone Rainer foi a figura aglutinadora e sua pesquisa, Continuous Project Altered Daily $C P-A D$, foi essencial para a formação do grupo.

A obra Continuous Project Altered Daily - CP-AD, de Robert Morris, era um work in process que enfatizava a ação do artista sobre os objetos que iam de pedaços de metal bruto, latas, sujeira, placas de madeira, feltro etc.. Morris usava - espaço do museu como ateliê e o público podia acompanhar seu desdobramento ao longo dos dias em que a obra permaneceu instalada. 
Yvone Rainer procurava uma transposição da obra de Morris para o campo da dança: em 1969, o mesmo ano em que o artista apresentou sua instalação na Leo Castelli Gallery, ela iniciou sua pesquisa com Barbara Dilley. Seu principal foco era permitir a irrupção do espontâneo em cena, ou da situação de ensaio. Alguns meses depois, se apresentaram ao longo de três dias em diversas áreas do Whitney Museum, seguindo a ideia original de Morris.

Basicamente, a ação em $C P-A D$ do Grand Union consistia em manipular objetos de diferentes maneiras: ora em uma sequência marcada de movimentos, ora parando para fazer comentários e perguntas. Eles exploraram alguns momentos do processo de criação e de ensaios em dança: pesquisar, refazer, marcar, combinar movimentos livres com sequências coreográficas, ressaltando o contraste entre o virtuose e o cotidiano, o profissional e o amador, ao som de músicas que variavam entre River Deep, Mountain High de Ike e Tina Turner e Here Comes the Sun dos Beatles. Faziam parte do conjunto de objetos: um par de asas grandes, travesseiros e almofadas, caixas de papelão, papeis, um pedaço de borracha de mais ou menos $1,80 \times 60 \mathrm{~cm}$, entre outros que Rainer chamava de arte corporal e complementos ${ }^{16}$. Minutos antes da apresentação, no Whitney Museum, eles não sabiam exatamente o que iriam apresentar, mas apoiavam-se em enunciados para a execução de tarefas.

A maneira de se apresentarem também era inovadora para a época: vestiam camisetas, calças jeans e calçavam tênis. O silêncio era interrompido por uma risada, uma palavra ou comentários breves sobre o que acabavam de realizar, entremeados por uma leitura coral de um texto ou por corridas coletivas em espirais e círculos. Segundo Sally Banes, a apresentação estava envolvida por uma atmosfera vibrante e lúdica, contagiante (Banes,1978a, p.43-49).

Rainer não buscava os conteúdos simbólicos da dança, mas os seus movimentos próprios, assim como fez Merce Cunningham. Diferente da dança moderna preocupada em expressar as matrizes mitológicas carregadas de simbologia, Yvone Rainer e seus parceiros estavam preocupados em abolir a expressão carregada e substituí-la por faces neutras. Não se tratava mais de

${ }^{16}$ Body art adjunts. (Tradução nossa). 
dançar os mitos, tal como o fez a dança moderna, mas explorar a maneira que se investia a energia nos corpos.

Os artistas do Grand Union queriam chegar a uma técnica capaz de repensar o que é expressão e questionar a serviço "do que" ou "de quem" ela se coloca, em vez de investir em uma longa e fatigante formação técnica. Eles pretendiam inverter essa conduta, tornando seus procedimentos mais democráticos: a maneira horizontal com que criaram seus experimentos, a supressão dos elementos espetaculares como luz, cenário e figurino ou o deslocamento das apresentações em casas de espetáculos para espaços alternativos como museus e ginásios, são alguns exemplos desse pensamento.

O grupo aboliu por completo a ideia de glamour ou de corpo idealizado e iniciou-se, assim, um processo de recusas que culminou com a declaração do fim da dança. Rompeu-se, definitivamente, qualquer relação com a ficção, a ilusão, a sedução ou a subjetividade narcísica. Foi abolido o espaço cênico que separava espectadores e bailarinos. O olhar "no horizonte", típico dos bailarinos, foi substituído pela ideia de presentidade. Negou-se qualquer mimetismo, interior ou exterior - seja na utilização de imagens internas ou externas. Rainer sempre preferiu, por exemplo, imagens maquinais ao invés de animais, para evitar justamente a irrupção de uma personagem: preferia a imagem de um tonel em vez da de um fauno, e a de um avião em vez da de um pássaro. Ela queria eliminar qualquer afetação.

O Grand Union substituiu a preparação marcada e prévia das apresentações públicas por uma intensificação da intimidade entre seus integrantes. Para isso, desenvolveu um vocabulário interno próprio, e ampliou a percepção das insurgências espontâneas, assim como a capacidade de resposta em um encadeamento contínuo de ações.

As afinidades de Mary Overlie com os procedimentos do Grand Union não se restringiram apenas uma apropriação conceitual, mas se deram em outras parcerias e filiações. Ela aplica o contact Improvisation de Steve Paxton na preparação para a prática do Six Viewpoints. Também não é por acaso que uma das suas primeiras coreografias recebe o título de Small Dance, ou pequena dança, 
conceito utilizado por Paxton para denominar o movimento microscópico realizado pelo corpo no simples ato de manter-se de pé (Overlie, 2016, p.135).

\section{Natural history of the American dancer}

Em 1971, Mary Overlie parte para Nova Iorque em sua segunda carona, dessa vez ao lado de Yvonne Rainer, para participar de um evento chamado Names com Barbara Dilley na galeria 112 Greene Street ${ }^{17}$. Posteriormente, esse mesmo grupo de artistas formado em São Francisco por Dilley continuaria a trabalhar junto: Carmen Beuchat, Suzanne Harris, Cynthia Hedstrom, Rachel Lew e Mary Overlie o nomearam Natural history of the American dancer - lesser known volumes 1-25, um grupo de improvisação em dança interessado em integrar escultura, instalação, manipulação de objetos e movimentos corporais que perduraria até 1974 quando Barbara Dilley, líder do grupo, foi convidada para desenvolver o programa do Departamento de Dança da Universidade de Naropa, no Colorado.

Segundo Mary Overlie, o jeito de o Natural History trabalhar era muito particular: quase nunca conversavam sobre o que estavam fazendo ou iam fazer, mas buscavam uma dança que surgisse da negação de procedimentos da dança moderna. Elas basicamente dançavam, e através dessa "dança improvisada", retiravam material. Ela denomina esse período como a "época em que se inventou a roda para trás" ${ }^{18}$, justamente para marcar essa fase em que reuniu os elementos que comporiam o Six Viewpoints e que teve início a partir do convívio com outros artistas que buscavam, assim como ela, um tipo de arte que emergisse de uma perspectiva totalmente diferente da convencional, ou seja, uma invenção já conhecida, mas em outro sentido.

O Natural History trabalhou em uma ação do artista Gordon Matta-Clark chamada Open House, de 1972. Ele alugou um contêiner e o estacionou em frente

\footnotetext{
17 Apesar de 112 Greene Street ser um endereço, ora nos referimos ao prédio, à rua, à galeria ou ao espaço, o que expressa a dificuldade de designação do lugar, justamente pela plasticidade de sua definição.

18 This era started for me when I came to New York to live with the artists who were looking at art from an entirely different perspective. Soho, January 1970. I joined them in "inventing the wheel backwards". Disponível em https://sixviewpoints.com/thesstems. Acesso em: 15 out. 2021.
} 
ao estúdio da 112 Greene Street. Depois, transformou seu interior em uma espécie de casa feita de restos de paredes, portas e janelas de demolição, porém sem cobertura. Em Open House, as dançarinas improvisavam, movimentando-se entre os estreitos espaços do contêiner. Trata-se de um dos projetos com forte impacto social, pois representava a ideia de uma "casa-lixo", como uma crítica ácida a uma cidade que não conseguia sustentar as pessoas que nela viviam (Barliant, 2012).

O prédio industrial na 112 Greene Street era um espaço alternativo onde artistas poderiam desenvolver ou exibir seus trabalhos, em qualquer linguagem artística. Inicialmente, foi comprado pelo casal Jeffrey e Rachel (Wood) Lew para ser casa e estúdio. Muitos outros artistas se juntaram a eles no bairro de SoHo, então despovoado e onde o custo de vida era muito barato. Gordon Matta-Clark, ao lado de Lew, ajudou a construir o piso térreo e o porão do prédio.

Frequentavam o espaço: Richard Nonas, Alan Saret, Alice Aycock, Bill Beckley, Louise Bourgeois, Chris Burden, Mary Heilmann, Joan Jonas, Dickie Landry, Dennis Oppenheim, Susan Rothenberg, Carolee Schneemann, Ned Smyth, George Trakas, and Jackie Winsor. Lá, havia concertos de Philip Glass e Steve Reich, apresentações de artistas do Grand Union, do Mabou Mines e do Judson Church Movement. Alguns deles não só trabalhavam como moravam nesse prédio, situado há poucas quadras da Washington Square onde fica a Judson Memorial Church. Foi um espaço que proporcionou o convívio e o diálogo intenso, bem ao espírito dos anos 1970: um lugar sem administração nem curadoria, do tipo portas abertas.

Liderados por Jeffrey Lew, artistas transformaram o espaço abandonado em um misto de galeria e espaço performático. Sua aparência rústica, apenas com suas colunas brancas das estruturas internas tão características, configurava o espaço ideal para acomodar trabalhos que não cabiam nas galerias do uptown. Uma escultura podia ser manipulada enquanto outros artistas faziam um buraco no chão. Tudo era possível ${ }^{19}$. Essas ações coletivas refletiam não apenas uma maneira diferente de se relacionar com o fazer artístico, mas tinham um claro posicionamento político. O 112 Greene Street é um lugar difícil de definir mesmo

19 De 10. a 28 de dezembro de 1972, quatro peças de Tina Girouard foram "ativadas" pelos artistas - entre eles o pessoal do Mabou Mines - que simplesmente chegaram, tiraram seus sapatos e, entrando um de cada vez, começaram a improvisar. (Peppiatt apud Fischer, 2012, p.77). 
nos dias de hoje, pois alternava suas atividades entre estúdio, galeria, residência e ponto de encontro.

Segundo Jessamyn Fiore, filha de Matta-Clark (Barliant, 2012), os artistas que frequentavam a Greene queriam causar um grande impacto sobre o que estava acontecendo na cidade de Nova Iorque, que a cada dia se abeirava de uma bancarrota, com uma massa enorme de pessoas sem casa para morar, vivendo uma tremenda decadência e pobreza urbanas. Os artistas desse período estavam muito ligados a esse contexto e extraíam dali temas e material para seus trabalhos. Vários artistas recolhiam das ruas, do lixo, o material para suas experimentações, como Claes Oldenberg, Robert Rauschenberg ou Gordon Matta-Clark.

A comida também exerceu um grande papel em ações desse período. É o caso de Tina Girouard, Richard Landry e Mary Heilmann que promoviam banquetes gratuitos. Em Dumpster Duplex, Matta-Clark, em uma segunda versão do Open House, construiu um segundo piso em seu contêiner, onde preparou um churrasco a céu aberto. Especialmente o SoHo, que na época não dispunha de muitos lugares para comer ou beber, o Food Restaurant, inaugurado por Carol Goodden e Gordon Matta-Clark, foi uma extensão natural do Open House.

Mary Overlie morou em um dos lofts do segundo andar do 112 Greene Street, dividido com Cynthia Hedstrom, outra integrante do Natural History, com o escultor Thom Cathcart e com o ator Terry O’Reilly, os dois últimos integrantes do então recém-formado grupo de teatro Mabou Mines. Sua experiência com o Natural History ampliou as possibilidades de atuação, não se restringindo a um espaço convencional. Pelo contrário, a intervenção em obras de escultores como Gordon Matta-Clark e Tina Girouard, dentre outros, ofereceu a pista que precisava para continuar em sua busca exploratória de uma técnica que considerasse fortemente a arquitetura.

O rompimento com o Natural History se deu porque elas começaram a discutir sobre dança, o que antes parecia acontecer como um processo mais prático de improvisação. E foi justamente dessa ruptura que o Viewpoints emergiu: "Eu estava procurando por eles e eles estavam lá. Eu apenas os removi do trabalho do Natural History e olhei para eles no chão do meu estúdio. Não parecia um ato 
de coragem, justamente porque eles estavam implícitos para mim" (Bogart, 2012, p.483) $)^{20}$.

Mary Overlie não determinou quais eram os seis Viewpoints logo de início. Pelo contrário, eles foram sendo selecionados ao longo de sua pesquisa com bastante flutuação desses seis componentes ${ }^{21}$.

Apesar de uma ampla lista de produções em que Overlie atuou como coreógrafa, destacam-se a seguir alguns trabalhos realizados na década de 1970, para melhor contorno e entendimento de sua produção durante o período da origem e do desenvolvimento do Six Viewpoints.

\section{Mabou Mines Theater Company}

O grupo Mabou Mines foi oficialmente fundado em 1970 por cinco artistas: os casais Ruth Maleczech/ Lee Breuer e Philip Glass/ JoAnne Akalaitis e o ator inglês David Warrilow. Os dois casais, por diferentes motivos, partiram para Europa em busca de novos conhecimentos e oportunidades. Akalaitis e Maleczech se encontraram em um treinamento físico com Jerzy Grotowski. A partir daí os casais se uniram ainda de maneira informal, mas com interesses comuns: visitaram o Berliner Ensemble e conviveram com o Living Theater, na época, em exílio voluntário.

Cinco anos depois, retornam para Nova Iorque. Mas para a montagem de seu primeiro espetáculo, Red Horse Animation, recolheram-se na casa do casal Glass e Akalaitis, na Itha de Cape Breton, Nova Escócia, Canadá, onde havia uma placa sinalizando as minas Mabou, que acabou dando o nome ao grupo. O desejo era desenvolver uma arte de linguagens híbridas (partituras corporais e utilização de objetos e de bonecos manipulados), música e dramaturgia autoral, mesmo que tomando por base textos de austeridade estética, tais como os de Samuel Beckett,

\footnotetext{
20 I had been looking for them I knew they were there. I just removed the Natural History work from them and looked at them on my studio floor. It doesn't seem like courage to me, because they seemed so implicit. (Tradução nossa).

${ }^{21}$ A saber, os Six Viewpoints são: Espaço, Forma, Tempo, História, Emoção e Movimento.
} 
Jean Genet e Harold Pinter (Cohn apud Warren, Rossman, Sherzer, 1987, p.175-176).

Apesar de Lee Breuer assumir o papel de diretor e dramaturgo do Mabou Mines, cada membro do grupo participava ativamente da criação das obras. As ideias do diretor serviam de base para as improvisações que exploravam gestos, ações, movimento e texto em um processo de múltiplas direções. Como conta Maleczech (Fischer, 2012, p.31), a sensação era de que várias pessoas estavam dirigindo de uma só vez, por meio de um diálogo intenso e franco entre os artistas, dotando os atores de uma enorme autonomia frente à criação. A consequência disso foi que alguns deles passaram a realizar seus próprios projetos, como Akalaitis e outros que, de forma mais extrema, vieram a romper com o grupo.

Em 1975, o grupo conquistou maior abrangência de público quando levou à cena três peças curtas de Samuel Beckett. Duas remontagens, Comédia (Play) e Vai e Vem (Come and Go) e uma estreia, O despovoador (The Lost Ones). Thom Cathcart, então cenógrafo, concentrou o público de apenas cinquenta pessoas por sessão, em um cilindro feito de cortinas pretas pesadas para que conseguisse manter um blackout. Os espectadores eram convidados a tirar seus sapatos e deixar suas bolsas do lado de fora da sala. Entravam, então, em outro ambiente, na penumbra, onde se sentavam em almofadas e em cubos espalhados desalinhadamente pelo espaço e, então, mergulhavam no escuro total. Ouvia-se a música de Philip Glass, depois uma voz eloquente, a luz fazia emergir finalmente a figura do ator. Para assistir às duas outras peças, o público ia se deslocando pelos espaços, perdidas em uma encenação arrebatadora (Marranca apud Fischer, 1975, p.103).

A montagem recebeu o Obie Awards de melhor ator para David Warrilow em 1976. Segundo a crítica, a aparência esguia e a voz circunspecta, marcas do ator britânico, tornaram-no tão identificado com Beckett que parecia o alter ego do autor (Gussow, 1995).

Mary Overlie se associou ao grupo por volta de 1972, iniciando uma parceria duradora como preparadora corporal. A pesquisa ateve-se às obras de 1970 a 1978 - período de desenvolvimento inicial do Six Viewpoints - em que participou de três produções. O trânsito entre linguagens, característica do período, fica 
evidente, seja na colaboração da dançarina para o grupo de teatro, como também na participação do ator David Warrilow em duas de suas criações coreográficas.

Overlie contribuiu com a coreografia e encenação dos seguintes espetáculos dirigidos por Lee Breuer: The Saint and the Football Players (1973), The Lost Ones (1979) e Red Beads (2005). Seu trabalho com Mabou Mines também incluiu colaborações com a diretora JoAnne Akalaitis nas produções teatrais: Cascando (1977), Dressed Like an Egg (1978) e Dead End Kids (1983).

\section{The Saint and the Football Players}

Apesar da monumental produção envolvida, The Saint and the Football Players excursionou por cinco países contrariando as expectativas. Em seu elenco, dezessete atores vestidos como jogadores de futebol americano (com capacetes, ombreiras, chuteiras e uniformes brancos, porém sem número) movimentavamse em um campo. A ideia de Breuer era encenar o poema Xerox Poem de Jack Thibeau, em que se vê, na imagem granulada da fotocópia, a justaposição de uma "mulher santa" na posição de um touchdown²2, típica jogada dessa modalidade esportiva.

Lee Breuer, diretor do espetáculo, descreve a peça como uma total descarga masculina (Fischer, 2012, p.130). Ele, no entanto, subverteu a ordem machista e colocou os homens como jogadores e as mulheres como juízas. A peça foi considerada uma mistura de arte e esporte, sendo convidada a participar de festivais de teatro e de dança. Esse foi o primeiro espetáculo que conferiu a Breuer o crédito de dirigir e realizar eventos de grande porte: além de um elenco numeroso, alguns carros faziam parte da cena. The Saint and The Football Players, que estreou em 1973, agradava tanto ao público de arte quanto ao público em geral, apesar de ser considerada pela crítica como um desafio devido ao seu formalismo lúdico.

O espetáculo dividia-se em duas partes: a primeira, concentrada na ação dos 
jogadores, e a segunda, na relação entre os jogadores e os carros. Mary Overlie, responsável pela parte corporal, utilizou-se do Contact Improvisation de Steve Paxton que consiste, basicamente, em uma movimentação que parte de forças contrárias a partir do contato entre dois corpos. Ela aplicou com o elenco de vinte dançarinos o que era chamado de driping, ou seja, chocar o próprio corpo contra outro corpo, ou contra os carros, e escorregar lentamente, descendo até esparramar-se no chão. (Overlie apud Fischer, 2012, p.132).

Mary Overlie disse ter tido dificuldade em trabalhar com Lee depois de The Saint and The Football Players. Ela considera esse afastamento consequência da alta demanda do diretor, muito exigente, e também de certo glamour no jeito de ele trabalhar, o que parecia ir contra a visão que ela tinha de um trabalho coletivo em grupo, ou de um processo mais horizontal. Segundo a coreógrafa, apesar da dificuldade na maneira de trabalhar, o resultado foi colossal, e em certos momentos, surpreendentemente belo (Fischer, 2012, p.132).

\section{Cascando}

Cascando foi a primeira peça dirigida por JoAnne Akalaitis, até então atriz do Mabou Mines, e foi o pontapé inicial do que iria desenvolver posteriormente em Dressed Like an Egg e Dead End Kids. Nesse trabalho, Yvone Rainer foi uma grande influência, usando os acontecimentos de maneira mais solta à narrativa, mas nem por isso, subjetiva. Havia uma conexão que era plástica, por meio da forma, e que tinha a ver com o espaço, onde as associações entrelaçavam os acontecimentos (Akalaitis apud Fischer, 2012, p.125)

Trata-se de uma peça radiofônica, escrita por Samuel Beckett em 1961, tem no subtítulo: Invention radiophonique pour musique et voix. Foi transmitida na França, em 1963, com música do compositor franco-romeno Marcel Mihalovici. A peça é um jogo constante entre a música e duas vozes: uma que tenta inutilmente finalizar a narrativa enquanto outra interrompe constantemente fazendo com que a primeira reinicie infinitas vezes a história.

Na montagem do Mabou, realizada em 1973, Akalaitis optou por sobrepor 
algumas falas sem alterar, no entanto, a dramaturgia. Ela também trocou a música original de Marcel Milhalovici pela trilha de Phillip Glass e distribuiu as falas, inicialmente divididas em dois, para sete atores. A essência da peça está mais no ato de narrar que na narrativa em $\mathrm{si}^{23}$. Em cena, via-se uma mulher e quatro homens ao redor de uma mesa, mais um homem no canto e ainda outro sentado em uma cadeira de balanço. O cenário recuperava a atmosfera de uma garagem subterrânea, com sucata amontoada, objetos velhos e quebrados, fotos, um casco de tartaruga e um urso polar de souvenir.

Partindo da premissa de uma fratura da realidade, Mary Overlie criou partituras corporais sem seguir uma lógica entre cada célula de movimento e buscou ações que não tivessem uma conexão direta com o texto de Beckett, nem revelassem uma relação emocional com ele. Segundo a coreógrafa, essa partitura permitiu que os atores trabalhassem o texto de maneira mais leve e sem esforço (Overlie apud Fischer, 2012, p.126).

Os sete atores da peça (entre eles o escultor Tom Cathcart e um violoncelista), ao mesmo tempo em que seguiam cada qual uma sequência de ações próprias, produziam sons que acompanhavam a narração - não de maneira ilustrativa, mas criando associações paralelas e inconscientes. Os atores se moviam em uma dança lenta, parecida com o tai chi chuan ${ }^{24}$, alterando a percepção do tempo e espaço, como se buscassem uma saída daquela situação cênica e, em última instância, do próprio realismo (O’Reilly apud Fischer, 2012, p.126).

Ele ainda conta que sua intenção, ao criar a luz do espetáculo, era retirar toda a cor, mas, ao invés do contraste, ele preferiu o cinza desbotado. Na reta final de produção de Cascando, que durou aproximadamente sete meses, Terry colocou duas torres laterais de luz que redimensionaram o espaço. Segundo Mary Overlie, a luz editava a sequência de movimentos, fragmentando a imagem, o que provocava um efeito vertiginoso. Não fica claro, na descrição, no entanto, se as luzes permaneciam acesas, se piscavam ou se causavam ambos os efeitos, mas

${ }^{23}$ It is the telling more than the story itself that is the essence of the play (Tradução nossa). Disponível em: https://www.maboumines.org/production/cascando/ Acesso em: 15 de out. 2021.

${ }^{24}$ Arte marcial chinesa em que se realiza, lentamente, uma sequência de movimentos. 
esse entrar e sair da luz traduzia cenicamente o próprio título da peça: Cascando, que vem de "cascata" e, que em termos musicais, indica o "decrescendo", a diminuição progressiva da intensidade do som. Essa sensação também era acentuada pela velocidade lenta dos movimentos que iam se desacelerando ao longo da peça (O’Reilly apud Fischer, 2012, p.156).

Em 1976, seria a vez de JoAnne Akalaitis levar o Obie Awards pela direção de Cascando.

\section{Dressed Like an Egg}

Enquanto Lee Breuer estava totalmente entregue a uma pesquisa voltada à articulação de uma narrativa que alternava elementos autobiográficos com o tema da memória, Akalaitis estava explorando o tema da emancipação. Ela estava interessada, nesse seu segundo trabalho como diretora, em convocar a si própria e seus parceiros artísticos para viver uma espécie de celebração. Dressed like an Egg, de 1977, apresentava o paradoxo da liberdade e do aprisionamento no compromisso amoroso. Isso deflagrava um sintoma da crise que o Mabou Mines enfrentava, decorrente dos esgarçamentos das relações.

Sua fonte básica de pesquisa foi a vida e a obra da escritora francesa SidonieGabrielle (1873-1954), de codinome Colette, autora da conhecida série Colette e do romance Gigi, entre outros. Sua obra tem como temas o amor idílico, os papéis sexuais e as questões de gênero e de compromisso, reflexos de sua vida turbulenta. Sidonie-Gabrielle foi casada três vezes, abandonou uma das filhas para dedicar-se à vida de artista, teve relacionamentos extraconjugais e foi apaixonada por Mathilde de Morny, Marquesa de Belbeuf, conhecida como Missy. Dedicou anos de sua vida ao music hall, atuando no famoso Moulin Rouge. Lá, realizou um número em que beijava ardentemente Mathilde, a ponto de a polícia, certa vez, suspender o show. Dentre seus parceiros artísticos destacava-se Maurice Ravel. Julia Kristeva a considera a rainha da bissexualidade e dedicou um livro especialmente à sua figura (Kristeva, 2002).

Akalaitis tinha assim o argumento perfeito para discutir sua função dentro do 
Mabou Mines, bem como seu papel na arte. A dramaturgia, assinada também por Akalaitis, estava dividida entre escritos pessoais, trechos originais de Colette e também de outros autores. Ela utilizou a estética do music hall, um recurso em chave crítica, que the possibilitou discutir com ironia o papel da mulher em plenos anos 1970, misturando diferentes camadas a vida de artista e de mulher, seus desejos sexuais em conflito com seu estado civil e os padrões de comportamento da sociedade.

Ao contrário da experiência com Breuer, a parceria entre Mary Overlie e JoAnne Akalaitis se deu de maneira tão envolvente, em uma comunicação tão fluida, que era difícil definir sua contribuição (Overlie apud Fischer, 2012, p.157). A diretora lançava ideias sobre o modo como gostaria que os atores dissessem o texto, como por exemplo, movimentando apenas os pés, muito silenciosamente, ou que o personagem Ovo participasse da coreografia junto com os atores. Mary Overlie saía com essas informações e na semana seguinte respondia: "um ovo pode dançar!", afirmando, assim, uma intensa parceria. Elas estavam interessadas em desconstruir os elementos do teatro e reconstruí-los, e esse processo estava relacionado à ruptura com paradigmas da dança e do teatro, criando um novo instrumental para isso (Fischer, 2012, p.159).

O Mabou Mines era um grupo com uma dinâmica imersiva e de diálogos artísticos intensos. Seus processos de criação eram colaborativos, coletivizados, e foi nesse grupo que Mary Overlie teve a chance de aprimorar os elementos que constituem a linguagem teatral. Também foi em decorrência de seu convívio com o grupo que ela teve a chance de dominar os elementos que constituem a linguagem teatral para então desconstruí-los e, finalmente, condensá-los em seus Six Viewpoints. Também foi em decorrência de seu convívio com o grupo que ela convidou o ator David Warrilow ${ }^{25}$ para participar de sua estreia como coreógrafa.

${ }^{25}$ A partir de 1979, Warrilow afirma-se como o ator das obras becketianas sendo, inclusive, eleito pelo próprio Beckett. Ele dedicou sua vida a essas montagens e, apesar de ter participado de outras obras, sempre manteve o tom sóbrio e irreverente, sua marca como ator. 


\section{Trabalhos próprios - Window Pieces e Painter's Dream²}

Glassed Imagination e Glassed Imagination // foram apresentadas pela primeira vez em 1977, na recém-inaugurada galeria situada no SoHo, a Holly Solomon. A apresentação aconteceu na fachada da galeria e, através do vidro, viase Wendell Beavers, Mary Overlie e David Warrilow um ao lado do outro. A vitrine era composta de duas secções cada uma com mais ou menos dois metros de comprimento, dois metros de altura e oitenta centímetros de profundidade cada: um espaço exíguo para três pessoas. A plateia assistia da rua e da calçada em meio ao movimento natural dos carros e dos transeuntes. Segundo o crítico Terry Curtis Fox, a apresentação era uma mistura da austeridade estética com a alegria de uma festa de rua (Fox, 1978).

Os três executavam uma sequência individual de gestos (braços, troncos e cabeça, com alguma alternância de peso) que se repetia. Com olhar introspectivo, eles falavam de maneira inaudível. A coreografia trabalhava com revezamento de combinações: por vezes solo, dupla e trio - ora em uma mesma secção da vitrine, ora nas duas simultaneamente e, apesar da estreiteza do espaço, arriscavam alguns deslocamentos. Havia um momento em que os três, juntos, viravam-se de costas e iniciavam uma misteriosa sequência gestual bastante focada nas mãos e nos espaços vazios, forçando-os a explorar outros planos.

À primeira vista, tinha-se a impressão de que o trabalho se organizava não como uma série fixa de movimentos, mas como enunciados ou princípios de improvisação. Porém, os momentos mais livres eram contrapostos por encadeamentos de movimentos em uníssono e elaborações rítmicas bastante complexas. Depois, eram exploradas várias combinações entre gestos expressivos e abstratos, agora com duas cadeiras, cada qual em uma das secções da vitrine ${ }^{27}$.

No artigo de Terry Curtis Fox, a participação do ator David Warrilow foi o

${ }^{26}$ Há informações conflitantes quanto à estreia de Mary Overlie como coreógrafa. Em seu site, Small Dance aparece em 1976 e Window Pieces: Glassed Imagination, em 1977. Já em sua biografia ao final de seu artigo em Training of the American actor, Painter's Dream surge como seu debut. De qualquer maneira, Painter's dream foi a obra que the conferiu reconhecimento como coreógrafa e as apresentações estavam com ingressos esgotados no The Kitchen.

${ }^{27}$ Window Pieces - Wide shot, New York Public Library for Performing Arts, 1977. Infelizmente, o registro acaba antes do final da peça aos 96 minutos de duração. 
grande destaque da peça. A austeridade estética, conferida pelo crítico do Village Voice, foi quebrada quando o ator entrava em uma das secções, vestindo um paletó e um lenço amarrado no pescoço. Desempenhando um conjunto de movimentos e gestos cotidianos, ele reclinava-se sobre uma das paredes internas da vitrine, sorria para o público, falava, ajeitava os bolsos, acendia um cigarro e fumava pensativo, quebrando o formalismo da coreografia com seu olhar doce e melancólico. O público reagia de imediato, rindo. O ator criava uma figura patética, inspirada no exagero melodramático de artistas como Charles Ludlam e as figuras clássicas do cinema, como Greta Garbo (Fox, 1978). No entanto, a delicadeza e a complexidade dos movimentos de Mary Overlie também impressionavam pela qualidade de gestos limpos, claros, e apresentava uma figura misteriosa que parecia esconder a origem de seus movimentos. Era como se ela dançasse movida por um forte impulso pessoal, mas longe de ser emotiva. A prática do Small Dance $^{28}$, de Steve Paxton, parece ter exercido grande influência, também nessa criação.

Já a coreografia Painter's Dream foi apresentada pela primeira vez em 1978 com ingressos esgotados no The Kitchen, em Nova lorque. O registro existente dessa obra está no video The Camera in the Body's Hands. Painter's Dream, produzido no mesmo ano e com a voz em off de Overlie comentando a obra. A crítica Jennifer Dunning, do New York Times, fez o seguinte comentário: "é um trabalho de dança tão delicado quanto o mundo interior de uma concha"29.

A concepção da obra surgiu da comparação do trabalho do pintor ao do coreógrafo. De modo geral, o pintor olha o que pinta, alternando a ação e a observação em seu processo de criação. Mary Overlie partiu desse princípio disparador e utilizou a sala como uma tela em branco.

A peça começava na penumbra. Aos poucos o espaço ia se desvelando e

\footnotetext{
28 Small Dance é a designação dada por Steve Paxton aos micromovimentos de ajuste de equilíbrio quando se está em pé ou parado; é a resposta do corpo à força da gravidade e está relacionada à fase primeira de investigação do Contact Improvisation, técnica desenvolvida posteriormente por ele. Seus primeiros registros de experimentação datam de 1972.

29 It is a dance work as delicate as the inner world of a shell. (Tradução nossa). Disponível em: https://www.nytimes.com/1987/12/12/arts/dance-mary-overlie-and-sarah-skaggs.html Acesso em: 15 out. 2021.
} 
Mary Overlie emergia, vestida de cinza, em movimentos sutis, como que penetrando pela primeira vez o espaço vazio. A quase ausência de luz, no entanto, ressaltava os sons que preenchiam o espaço: os carros e vozes que vinham da rua, os passos delicados sobre o chão de madeira. Aos poucos a arquitetura se revelava e nela, outros três dançarinos vagavam sem rumo.

Mary Overlie conta que, para ela, a forma é um elemento importante na estrutura de uma coreografia e não foi à toa que incorporou Forma como um dos elementos do Six Viewpoints. Ela explica que, como a comunicação na dança se dá em boa parte pela presença viva dos performers, ela dispôs nessa coreografia dois estados de presença contrastantes entre si: David Warrilow e os demais dançarinos. Além disso, outro mote de Painter's Dream era justamente essa sensação de penetrar pela primeira vez um espaço vazio e perpetuar essa sensação ao longo de todo o trabalho. ${ }^{30}$

Nessa obra, David Warrilow invadia a sala com roupas berrantes: colete rosa, sapatos brancos e calças vermelhas (Banes, 1978b, 30) ${ }^{31}$. Ele parava mais ou menos ao centro da sala, interrompendo bruscamente a caminhada dos dançarinos que, nesse momento, iam ao seu encontro. Todos se reuniam em roda, como se tivessem parado o ensaio para ouvir os apontamentos de David Warrilow, que figurava como um coreógrafo ou action painter ${ }^{32}$, embora sua fala fosse inaudível para a plateia.

Segundo o crítico Terry Curtis Fox, a diferença entre os movimentos do ator e dos dançarinos era proporcional à diferença entre o gesto e a dança. Warrilow, apesar de ser um homem do teatro, não interpretava sua ação e sua atitude tampouco demonstrava qualquer grau de atuação sobre o palco. Ele não estava interessado em atrair ou repelir a plateia, mas concentrou-se apenas em criar uma

\footnotetext{
30 Trecho extraído de registro em video com texto em off com a voz de Mary Overlie: The Camera in the body's hands. Painter's Dream. U.S. Channel D (sem crédito do diretor), New York Public Library for Performing Arts, filme de 32 minutos, 1978.

${ }^{31}$ O registro do trabalho, observado por mim, foi feito em preto e branco, mas a descrição das cores - que consideramos relevantes em se tratando do tema da pintura - foram descritos no artigo de Sally Banes, 1978b, p 30-34.

32 Termo cunhado pelo crítico Harold Rosenberg para definir a atitude do artista Jackson Pollock sobre a tela. Disponível em: https://enciclopedia.itaucultural.org.br/termo350/action-painting

Acesso em: 15 out. 2021.
} 
presença, clara e bela, convincente o suficiente para servir de âncora aos movimentos dos dançarinos.

Refletindo sobre Painter's Dream em um artigo para a revista Dancescope, Mary Overlie afirma que sua estrutura, apesar de subjetiva, estava apoiada na narrativa composta predominantemente de associações entre os elementos, em vez de encadeamentos lineares (Sommer,1980, p.32).

Ao observar os registros em DVD dessas duas coreografias, é possível perceber que há várias sequências de movimentos bem marcados, repetidos simultaneamente por todos os dançarinos. Se há, portanto, momentos de improvisação, eles acontecem dentro de uma estrutura altamente elaborada e complexa, contrariando a ideia de improvisação como algo solto, espontâneo ou mal acabado. Apesar de os corpos dos dançarinos serem visivelmente treinados em códigos próprios da dança - como, por exemplo, o balé clássico - as coreografias de Mary Overlie são compostas de passos e gestos realizados a partir dos corpos e para os corpos dos dançarinos em cena, ou seja, a partir de um repertório pessoal dos artistas envolvidos, o que garante uma atuação equânime, inclusive a do ator David Warrilow.

\section{Mary Overlie Dance Company}

A Mary Overlie Dance Company esteve em atividade de 1977 a $1985^{33}$ e era formada por Wendell Beavers, Paul Langland, Nina Martin e outros colaboradores como Todd Merrell e Jan Wenk. Apesar de algumas coreografias realizadas em conjunto, a parceria se concretizou mais em um plano acadêmico, uma vez que Mary Overlie foi convidada para lecionar na Experimental Theather Wing, em 1978, e Wendell, Nina e Paul ingressaram como professores adjuntos, a partir de 1983.

Contrariando a formação em grupo, Small Dance, solo de vinte minutos de

${ }^{3}$ Há informações conflitantes sobre o período de existência da Mary Overlie Dance Company: se de 1976 a 1980 ou de 1978 a 1985; as duas constam no texto biográfico de Overlie em seu site eletrônico. Optamos pela informação que consta na apresentação de Wendell Beavers no site da Naropa University. As observações abaixo foram feitas a partir de registro em vídeo que reúne três coreografias: Small Dance, My Heart Dances e Richard Serra, com duração total de noventa minutos, realizadas em novembro de 1984 no Danspace, na St. Mark's Church. Descrevo apenas a primeira, pois, como dito anteriormente, o recorte histórico vai até 1980. 
duração de 1976, foi apresentado pela primeira vez no Whitney Museum em Nova Iorque. Acompanhada pela música de Joseph Haydn, a peça começa com Mary Overlie movendo-se muito lentamente, respondendo a impulsos centrais e internos e com foco na parte superior do tronco, entre nuca e peito. Sua qualidade é bastante fluida e suave. Ela usa um vestido curto, bege escuro, que compõe com sua palidez e a luz lateral ressalta seus ângulos fortes. Aos poucos, seus movimentos estabelecem uma relação entre cabeça, pescoço e palmas das mãos. Tem-se a impressão de que uma substância envolve seu corpo, provocando uma constante e densa vibração. Depois de alguns minutos, e com a ajuda do olhar, ela explora o espaço em um curto deslocamento, em que mantém os pés juntos e paralelos, em passos contidos. Seu corpo esguio, seu rosto exposto pelo cabelo curto e puxado para trás, confere à sua figura uma limpeza impecável que, somada à qualidade misteriosa de seus movimentos, dotam a coreografia de uma beleza extraordinária.

Wendy Perron, em sua crítica no SoHo Weekly News, relata que a entrada de Mary Overlie em cena fez o público mergulhar em um profundo silêncio. Ele completa dizendo que "sua figura atraiu a atenção pela habilidade pungente da artista em misturar autoridade e vulnerabilidade ao mesmo tempo" (Perron, 2013, p.21).

Nesse trabalho, fica mais evidente a conexão com o conceito Small Dance, usado por Steve Paxton e caracterizado aqui pela vibração irradiada por todo corpo ao tentar manter-se em equilíbrio. Mais uma vez o Contact Improvisation, assim como outros procedimentos experimentais da dança pós-moderna do Grand Union, reforça sua influência na maneira de pensar de Mary Overlie.

Mary Overlie foi uma das primeiras artistas a fazer parte do corpo docente do Departamento de Teatro da Tisch School of Arts para desenvolver um programa na Experimental Theater Wing e foi a partir dessa atuação que o Six Viewpoints ganhou corpo, a partir de 1978. 


\section{Referências}

BANES, Sally. Grand Union: Presentation of everyday life as dance. Dance Research Journal, vol.10, No. 2, p.43-49, 1978a.

BANES, Sally. II Mary's Overlie Painter's Dream. Dance-magazine. November, 1978b. Disponível em:

http://archive.thekitchen.org/wp-content/uploads/2017/01/Dance-Magazine-

Review.pdf Acesso em: 15 out. 2021.

BARLIANT, Claire. 112 Greene Street. The Paris Review Daily, 2012. Disponivel em: https://www.theparisreview.org/blog/2012/07/25/112-greene-street/ Acesso em: 15 out. 2021.

BOGART, Anne. Conversations with Anne - twenty-four interviews. New York City: Theatre Communications Group - TCG, 2012.

$\mathrm{COHN}$, Ruby. Mabou mines' translations of Beckett. In: Alan Warren Friedman, Charles Rossman, Dina Sherzer. Beckett translating/translating Beckett. University Park: Pensilvania State University Press, 1987, p.175-180.

CRAWFORF, Jane. Gordon Matta-Clark: In Context, p. 112 - catálogo da exposição Gordon Matta-Clark, que aconteceu na David Zwirner Gallery de 6 de junho a 19 de outubro de 2008. Disponível em: http://www.davidzwirner.com Acesso em: 15 out. 2021.

FISCHER, Iris Smith. Mabou Mines - Making avant-garde theater in 1970s. Ann Harbor: University of Michigan Press, 2012.

FOX, Terry Curtis. A Voice of his Own. Village Voice. New York City, out. 1978. p.67. Disponível em:

https://news.google.com/newspapers?nid=1299\&dat=19780731\&id=eA4QAAAAIBAJ \&sjid=aosDAAAAIBAJ\&pg=6501,2350604 Acesso em: 15 out. 2021.

GUSSOW, Mel. David Warrilow, 60, an actor who interpreted Beckett dies. New York City: New York Times, ago. 1995. Disponivel em:

https://www.nytimes.com/1995/08/29/obituaries/david-warrilow-60-an-actorwho-interpreted-beckett-dies.html Acesso em: 15 out. 2021.

KRISTEVA, Julia. Le génie feminine, la vie, la folie, les mots (tomo III). Colette. Paris: Fayard, 2002.

OVERLIE, Mary. Standing in space: the Six Viewpoints theory \& practice. Billings: Artcraft Printers, 2016.

PERRON, W. Through the eye of a dancer: select writings. Connecticut: Wesleyan 
University Press, 2013.

PIRSIG, Robert. Zen and the art of motorcycle maintenance. New York: Willian Morrow \& Company Inc., 1999.

PRECIOSO. Daniel. Os Diggers de San Francisco nos sixties: apropriações de um movimento inglês seiscentista. Revista de História Comparada, Rio de Janeiro, v. 12, no. 2, p.116-138, 2018.

RINALDI, Miriam. Viewpoints Teoria e Prática. Tese (Doutorado em Teatro) - Escola de Comunicações e Artes - Universidade de São Paulo, São Paulo, 2016. Disponível em:

https://teses.usp.br/teses/disponiveis/27/27156/tde-06022018-094418/pt-br.php Acesso em: 15 out. 2021.

SCHONTZLER, Gail. Montana's legendary art pioneer: Bob and Gennie DeWeese. Bozeman Daily Chronicle. Bozeman: dez. 2011. Disponível em https://www.bozemandailychronicle.com/100/newsmakers/article 1c0afdfc2ebe-11e1-b4ab-001871e3ce6c.html?mode=print Acesso em: 15 out. 2021.

SOMMER, Sally R. Mary Overlie - I was a wild Indian who happened to dance. The Drama Review, New York City: v. 24, n. 4, 1980.

The Camera in the body's hands: Painter's Dream. (Sem créditos). New York City: New York Public Library for Performing Arts, Jerome Robbins Dance Division. DVD, de U.S. Channel D, 1978, 32 minutos. Identificador: RLIN/OCLC: NYPY96-F524 NYPL catalog ID (B-number): b12684594 - Universal Unique Identifier (UUID): 18162fc0-7af1-0135-6f8a-0690c79455ae.

Recebido em: 30/08/2021

Aprovado em: 23/11/2021 